https://doi.org/10.33263/BRIAC11.009014

Volume 1, Issue 1, 2011, 009-014

Received: 7.02.2011 / Accepted: 12.02.2011 / Published on-line: 15.02.2011

\title{
Detection of enteropathogenic Escherichia coli (EPEC) using Multiplex PCR
}

\section{Grațiela Pîrcălăbioru ${ }^{1, *}$, Stavros Plessas ${ }^{2}$, Eugenia Bezirtzoglou ${ }^{2}$, Aristotelis Papageorgiou ${ }^{3}$, Athanasios} Alexopoulos $^{2}$, Ioanna Mantzourani ${ }^{2}$, Coralia Bleotu ${ }^{1}$, Carmen Chifiriuc ${ }^{1}$, Veronica Lazăr ${ }^{1}$

\section{ABSTRACT}

Intestinal pathogenic Escherichia (E.) coli strains are a major cause of worldwide morbidity and in some cases, mortality. Several pathological types of E.coli have been characterized based on their different virulence genes and also on their pattern of adherence to tissue culture cells. Among these pathovars, enteropathogenic E.coli (EPEC) strains have a high prevalence in clinical samples. EPEC are diarrheagenic strains which produce characteristic histopathological lesions known as attaching and effacing $(\mathrm{A} / \mathrm{E})$ on intestinal cells and do not produce Shiga or verotoxins. One useful tool in distinguishing this type of strains is represented by the PCR technique. The purpose of this study was to find a new, reliable protocol in order to identify EPEC strains from clinical and river water samples. We focused not only on the detection of the EPEC bundle forming pili specific gene but also on two other genes, one conserved in all Enterobacteriaceae (the gene for elongation factor $\mathrm{Tu}$ ) and the other in a conserved region specific for E. coli (the gene for the heat shock protein GroEL).

Keywords: Escherichia coli, EPEC, Multiplex PCR, bundle forming pili, GroEL, Tu

\section{Introduction}

E. coli is a facultative anaerobic bacteria which is part of the human normal microbiota. Some strains though can cause enteric disease with various types of symptoms such as diarrhoea, colitis and in some cases uremic syndrome $[1,2]$. Infection with pathogenic E. coli strains is closely linked to poor sanitation and personal hygiene and also it can be caused by the consumption of contaminated water from wells, rivers, and other surface waters [3-5].

Based on the clinical signs observed during infection, on the presence of different virulence genes (chromosomal and plasmidial) and also on their pattern of adherence to tissue culture cells (HEp-2 or HeLa cells), at least six different pathotypes of diarrhoeagenic E.coli were characterized: enteropathogenic E. coli (EPEC), enterotoxigenic E. coli (ETEC), enterohaemorrhagic E. coli (EHEC), enteroinvasive E. coli (EIEC), enteroadherent or enteroaggregative E. coli (EAEC) and diffuse adherent E. coli (DAEC). Among these E.coli pathogenic strains, in most developing countries, EPEC, ETEC and EAEC are the most common cause of infectious diarrhoea in young children $[6,7]$.

In vitro assays used for differentiation of these strains such as cell culture and cytotoxicity are expensive, time-consuming and require expertise which may be lacking in some diagnostic

\footnotetext{
${ }^{1}$ Department of Microbiology Immunology, Faculty of Biology, University of Bucharest,Romania

*Corresponding author e-mail address: gratiela87@gmail.com

${ }^{2}$ Laboratory of Microbiology, Biotechnology \& Hygiene, Faculty of Agricultural Development, Democritus University of Thrace, Greece

${ }^{3}$ Department of Forestry,Environmental Management \& Natural Resources,Democritus University of Thrace, Greece
} 
laboratories. Thus, it is important to distinguish diarrheagenic strains from non-pathogenic members of the normal flora using different fast and sensitive methods among which PCR amplification of the virulence genes is an important tool. During the last years studies have concentrated upon the detection of $E$. coli pathogenic type using Multiplex PCR [1, 6, 8-9]. In 2000, Pass et. al. developed a Multiplex PCR assay in order to distinguish different virulence genes in $E$. coli such as heat labile and heat stabile toxin, verotoxin types, cytotoxic necrotizing factors (CNF1, CNF2), attaching and effacing (eaeA), enteroaggregative (Eagg) and enteroinvasive (Einv) mechanisms and genetic support [10].

EPEC strains are moderately invasive and they bind the host intestinal cells by help of an adhesin known as intimin. Adherence to the intestinal mucosa leads to changes in the model of actin arrangement in the host cell. Changes in intestinal cell ultrastructure due to "attachment and effacement" is likely the prime cause of diarrhea in patients infected with enteropathogenic strains [11]. Typical EPEC strains produce bundle forming pili (BFP), which are long, flexible, rope-like structures composed of intertwining fibers $[11,12]$.

Thus, the purpose of this study was to highlight the presence of EPEC in clinical and seawater isolates using a novel PCR approach with 3 pairs of primers: one pair specific for BFP, major virulence factor in enteropathogenic $E$. coli strains, the second pair specific for chaperonin GroEL (with sequences specific for E. coli) and finally a pair of primers designed in order to highlight all the Enterobacteriaceae strains.

\section{Experimental section}

\subsection{Bacterial strains and DNA extraction.}

The bacterial strains were either clinical isolates or freshwater samples (Evros river, Greece). All the strains were initially identified as E. coli using classical microbiology assays (API20E profile system by BioMerieux). Initial molecular biology assays were performed on reference strains. For the DNA extraction, the bacterial strains were grown in Mueller Hinton broth and incubated 36 hours at $37^{\circ} \mathrm{C}$ with shaking. The DNA extraction was performed using a commercial kit (PureLink ${ }^{\mathrm{TM}}$ Genomic DNA Kit, Invitrogen) and also an extraction protocol developed in our laboratory. The DNA extraction protocol combines the thermal shock with the isopropanol precipitation. The result after the extraction is represented by both genomic and plasmid DNA. The protocol requires the following steps: $1 \mathrm{~mL}$ of bacterial culture was centrifuged at $12000 \mathrm{Xg}$ for $10 \mathrm{~min}$; the sediment was resuspended in $1 \mathrm{~mL}$ of PBS and centrifuged at $12000 \mathrm{xg}$ for $10 \mathrm{~min}$; this PBS washing was repeated 3 times. The final sediment was resuspended in $100 \mu \mathrm{L}$ sterile distilled water and thereafter the samples were incubated $30 \mathrm{~min}$ on a bath water set at $98 \mathrm{C}^{\circ}$ and the samples were then transferred at $10 \mathrm{C}^{\circ}$ for $10 \mathrm{~min}$ and afterwards again on bath water at $98 \mathrm{C}^{\circ}$ for $15 \mathrm{~min}$. In order to precipitate the nucleic acids, $100 \mu \mathrm{L}$ isopropanol were added and the samples were kept at $-20 \mathrm{C}^{\mathrm{o}}$ overnight. The next day, the samples were centrifuged $15 \mathrm{~min}$ at $13000 \mathrm{xg}$. In order to remove the protein contamination, the sediment was resuspended in $100 \mu \mathrm{L}$ of ethanol $70 \%$ solution, followed by a centrifugation at $14000 \mathrm{xg}$ for $10 \mathrm{~min}$. The supernatant was discarded and the samples were kept at room temperature in order for the remaining ethanol to dry (this is an important step because the remaining ethanol might inhibit the PCR reaction; more specifically this alcohol is prone to inhibiting the activity of the DNA polymerase). Finally the DNA sediment was dissolved overnight, at room temperature in $100 \mu \mathrm{L}$ of ultrapure distilled water. Additionally, in order to improve the purity of the DNA, an RNAse A treatment is needed (u sually $4 \mu \mathrm{L}$ of RNAse A is added to the samples kept afterwards for $2 \mathrm{~min}$ at room temperature). 


\subsection{PCR primer design.}

We have designed online primers for the genes of interest in order to identify E. coli strains. The primers were designed online and thereafter tested concerning the Tm (melting temperature) and the possibility of interaction between different primers (primer dimers) or primer secondary structures. These steps are important in order to achieve an optimal amplification in Multiplex PCR. The sequences of the genes were taken from GenBank and the primers were designed using an online application (on http://blast.ncbi.nlm.nih.gov/). All the designed primers were tested online using the BLAST application [13]. The DNA sequences of the primers and the sizes of PCR products are shown in Table 1.

Table 1. Primers used in the PCR amplification

\begin{tabular}{c|c|c}
\hline Gene & Primer sequence (5'-3') & Size of product (bp) \\
\hline$b f p A$ & BFP1 AATGGTGCTTGCGCTTGCTGC & $\mathbf{8 2 6} \mathbf{b p}$ \\
\hline & BFP2 GCCGCTTTATCCAACCTGGTA & \\
\hline$g r o E L$ & GR1: TCCGCGAAATGCTGCCGGTT & $\mathbf{5 2 1 \mathbf { b p }}$ \\
\hline & GR2: GGTCGCGTGCAGGGCATCTT & \\
\hline$e f-T u$ & EF1: CCCACTCTGCGTCGCCTTCC & $\mathbf{2 4 3 b p}$ \\
\hline & EF2: CCGATGCCGCAGACTCGTGA & \\
\hline
\end{tabular}

\subsection{PCR amplification conditions.}

Each DNA amplification was performed in $200 \mu \mathrm{l}$ microtubes using a $20 \mu \mathrm{l}$ reaction mixture (Invitrogen) which contained: $2 \mu \mathrm{L}$ PCR Buffer 10X, $0.4 \mu \mathrm{L}$ dNTPs $10 \mathrm{mM}, 0.6 \mu \mathrm{L} \mathrm{MgCl}_{2} 50 \mathrm{mM}, 1$ $\mu \mathrm{L}$ primer mix (forward+reverse), $0.1 \mu \mathrm{L}$ Taq Polymerase $(5 \mathrm{U} / \mu \mathrm{L}), 2 \mu \mathrm{L}$ DNA and DNAse free water $(13.9 \mu \mathrm{L})$. During our experiments, some concentrations of the mixture components varied in order to achieve a better amplification in Multiplex PCR (e.g. the $\mathrm{MgCl}_{2}$, the dNTPs and also the primers were used in various concentrations). All PCR primers were prepared as $100 \mathrm{mM}$ solutions which were frozen at $-20^{\circ} \mathrm{C}$. This storage method was used in order to prevent repeated thawing and freezing of the reagents which could have an influence on the PCR products. All amplifications were run in a thermocycler (BIORAD, DNA Engine) under the following conditions: initial denaturation at $94^{\circ} \mathrm{C}$ for $5 \mathrm{~min}$ followed by 35 cycles of $95^{\circ} \mathrm{C}$ for $1 \mathrm{~min}, 53^{\circ} \mathrm{C}$ for $50 \mathrm{sec}$ and $72^{\circ} \mathrm{C}$ for $50 \mathrm{sec}$. The final extension step was performed at $72^{\circ} \mathrm{C}$ for $5 \mathrm{~min}$. The products of the amplification were visualized by agarose standard gel electrophoresis in a $1 \%$ agarose gel stained with ethidium bromide $(10 \mathrm{mg} / \mathrm{ml})$.

\section{Results section}

EPEC was the first described pathotype of E. coli. In 1995, Neter et al. proposed to designate certain serotypes of $E$. coli associated with outbreaks of infantile diarrhea and in 1987, WHO recognized 12 serogroups belonging to EPEC pathotype (O:26, O:55, O:86, O:111, O:114, O:119, O:125, O:126, O:127, O:128, O:142, O:158). For decades, the mechanisms by which EPEC caused diarrhea were unknown and this diarrhoeagenic pathotype could be identified only on the basis of $\mathrm{O}: \mathrm{H}$ serotyping. In the past 20 years, however, the tools for identifying EPEC strains have been refined as the molecular basis of EPEC pathogenesis has begun to be elucidated and specific virulence genes have been discovered. The central mechanisms of EPEC pathogenesis called attaching and effacing $(\mathrm{A} / \mathrm{E})$, which is characterized by microvilli destruction, intimate adherence of bacteria to the intestinal epithelium, pedestal formation and aggregation of polarized actin and other elements of the cytoskeleton at sites of bacterial attachment [14]. The EPEC strains could be further classified as typical (eae the bfp genes and exhibiting a localized adherence pattern on cultured epithelial cells) (more frequent in developing countries) and atypical (eae,+ bfp-) (more frequent in industrialized countries) [15]. 
BFP are polymers of bundlin, a pilin protein that is encoded by the bfpA gene found on a large EPEC plasmid of 60Mda called pMAR2, which is influencing the expression of chromosomal genes for eaeA and intimin, an outer membrane protein. BFP probably plays a role in the bacterial colonization process in vivo because of theintertwine, creating a fibrous network connecting individual bacteria. The result consists in localized adherence, the capacity of EPEC to form defined microcolonies upon the epithelial cells and human intestinal tissue [16-17]. I

n a clinical study initialized by Bieber et al., volunteers fed mutant EPEC strains lacking BFP developed diarrhea at a much lower frequency and of less severity than did volunteers who received equivalent doses of an isogenic strain producing BFP [18]. In our study we focused on the rapid EPEC identification in samples of clinical and environmental origins using primers specific for BFP and also primers for conserved genes such as the gene for the elongation factor Tu, a new tool in Enterobacteriaceae phylogeny and for a heat shock protein, GroEL, an important factor in bacterial adaptation to stressful conditions.

Our experiments revealed the expected results. First of all we have highlighted the presence of the groEL gene and also of the elongation factor Tu (as shown in figures 1 and 2). In E. coli, the groEL gene is preceded by the groE promoter and groES gene in the groE operon [19]. GroEL, plays important roles in protein folding and assembly. This heat shock protein has an increased synthesis when the bacterial cell is exposed to various stress conditions.

Consequently, HSPs protect cells from the damaging effects associated with stressful conditions $[20,21]$. We have determined the presence of this gene and given the high specificity of the analyzed genetic region, groEL can be considered an useful tool for E. coli phylogeny [22]. Also, due to its essential role in protein biosynthesis, EF-Tu has been extensively investigated structurally and functionally and additionally, tuf genes have been previously used as a tool to determine phylogenetic relationships [23].

These two genes highlighted in figures 1 and 2 can be easily used in order to distinguish $E$. coli strains from other Enterobacteriaceae.

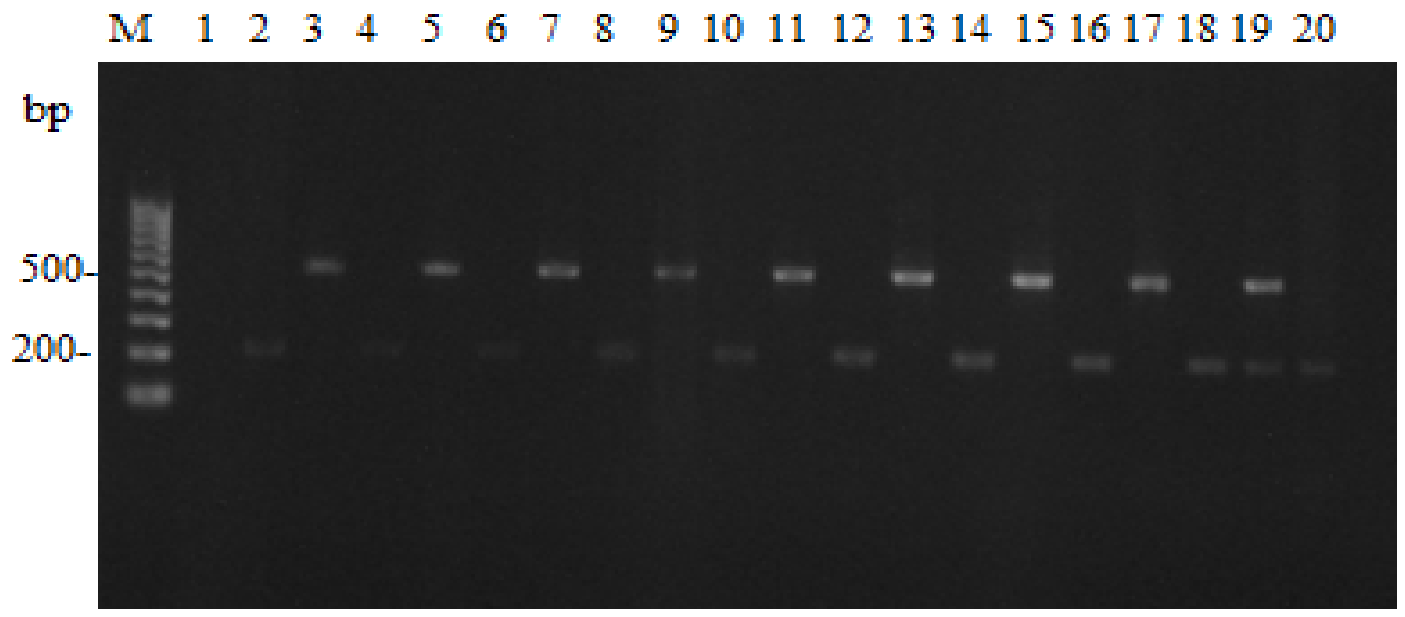

Figure 1. Single PCR results for the genes encoding the elongation factor Tu and chaperonin GroEL. The amplicons were evidenced by agarose gel electrophoresis.

Lane M-molecular size marker (100bp DNA ladder).Lane 1-negative control. Lanes 2, 4, 6, 8, 10, 12, 14, 16, 18, and 20- results of amplification for the gene encoding elongation factor Tu (243bp); Lanes 3, 5,7, 9,11, 13, 15 and 17- results of amplification for the gene encoding chaperonin GroEL (521bp);Lane 19-Multiplex PCR testing for both of the primers (ef-tu and groEL) with a reference strain 


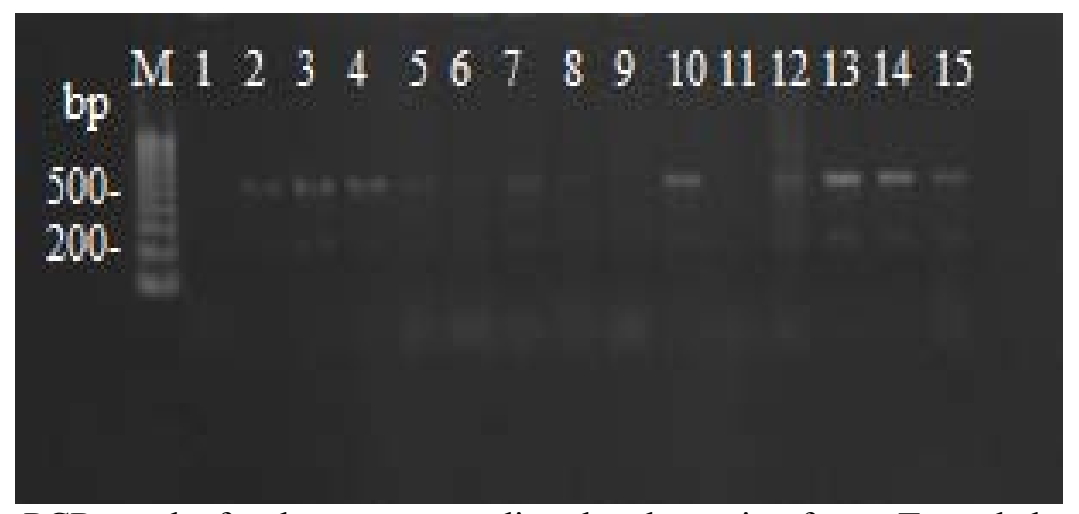

Figure 2. Multiplex PCR results for the genes encoding the elongation factor Tu and chaperonin GroEL. The amplicons were evidenced by agarose gel electrophoresis.

Lane M-molecular size marker (100bp DNA ladder).Lanes 1, 89, 11-negative controls (lanes 8,9 reveal the absence of PCR products using other DNA extraction protocols). Lanes 2-7 and 10, 12, 13, 14, 15-Multiplex PCR products (ef-tu and GroEL).

Out of the 12 samples shown in Figure 3,8 of the samples are positive for the bfp gene. Among the EPEC positive strains only one (sample loaded on lane 11) has an environmental origin, the other strains being clinical isolates.

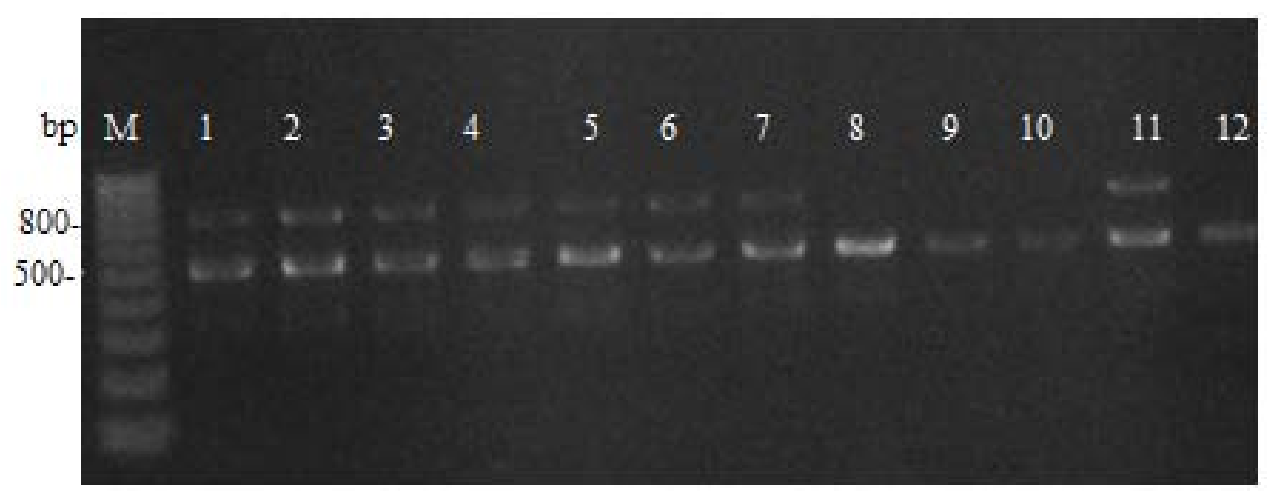

Figure 3. Multiplex PCR results for the EPEC genes (bfp and groEL). The amplicons were evidenced by agarose gel electrophoresis.

Lane M-molecular size marker (100bp DNA ladder). Lanes 1-7 and 11 highlight the presence of the bfp gene and also of the groEL gene (confirming the EPEC identity of these samples) while lanes 8, 9, 10 and 12 show only the groEL gene (thus, these samples are non-EPEC strains).

\section{Conclusions}

The distinction between different pathotypes of E.coli is a very important step for the diagnosis and the consecutive therapeutical approach. We concentrated on EPEC due to its high frequency, but we consider for the future the possibility of determining the other pathovars too. This new PCR approach could be used both in clinical diagnosis and also in phylogenetic studies due to concomitant detection of conserved genes.

\section{References}

[1] Rich C., Alfidja A., Sirot J.,Joly B., Forestier C., .Identification of human enterovirulent Escherichia coli strains by multiplex PCR, JCLA, 15, 2, 100-103, 2001

[2] Dupont HL, Diarrhoeal diseases in the developing world, Infect.Dis. Clin. North Am., 9, 313-324, 1995 
[3] Grasso GM, Sammarco ML, Ripabelli G, Fanelli I, Enumeration of Escherichia coli and coliforms in surface water by multiple tube fermentation and membrane filter methods. Microbios 103, 405, 119125,2000

[4] Welch P, David J, Clarke W, Trinidade A, Penner D, Bernsteins, McDougall L, Adesiyun AA. Microbial quality of water in rural communities in Trinidad, Rev. Panam. Salud, 2000

[5] Tumwine JK, Thompson J, Katua-Katua M, Mujwajuzi M, Johnstone N, Porras L, Diarrhoea and effects ofdifferent water sources, sanitation and hygiene behaviour in East Africa, Trop. Med. Int. Health 7, 9, 750-756, 2002

[6] Bii C.C., Taguchi T.T., Ouko L.W., Muita N. , Kamiya S., Detection of virulence related genes by multiplex PCR in multidrug-resistance diarrheagenic E. coli isolates from Kenya and Japan. Epidemol. Infect, 133, 627-633, 2005

[7] Wanke CA, Enteropathogenic and enteroaggregative strains of Escherichia coli: clinical features of infection,epidemiology, and pathogenesis, Curr Clin Top Infect Dis, 14, 230-252, 1994

[8] Kuhnert P, Boerlin P, Frey J, Target genes of virulence assessment of Escherichia coli isolates from water, food and the environment, Fed. Eur. Microbiol. Soc. Rev., 24, 107-117, 2000

[9] Toma C, Y Lu, N. Higa, N.Nakasone, I. Chinen, A. Baschkier, M. Rivas, M. Iwanaga, Multiplex PCR Assay for Identification of Human Diarrheagenic Escherichia coli, JCM, 41, 6, 2669-2671, 2003

[10] Pass M. A., R. Odedra, R. M. Batt, Multiplex PCRs for Identification of Escherichia coli Virulence Genes .JCM, 38, 5, 2001-2004, 2000

[11] Giron J. A., A. S. Y. Ho, G. K. Schoolnik, An inducible bundleforming pilus of enteropathogenic Escherichia coli, Science 254, 710-713, 1991

[12] Cravioto A.,. Gross R. J, Scotland S. M., Rowe B., An adhesive factor found in strains of Escherichia coli belonging to the traditional infantile enteropathogenic serotypes, Curr. Microbiol. 3, 95-99,1979

[13] Altschul SF, Gish W, Miller W, Myers EW, Lipman DJ, Basic local alignment search tool, J Mol Biol. 5, 215(3), 403-10, 1990

[14] Law D, Adhesion and its Role in the Virulence of Enteropathogenic Escherichia coli, Clin. Microbiol. Rev, 7,153-173, 1994

[15] Blanco M., Blanco JE, Dahbi G., Alonso MP, Mora A., Coira MA., Madrid C., Juarez A., Bernardez MI., Gonzales EA., Blanco J, Identification of two new intimin types in atypical enteropathogenic E. coli, Int Microbiol., 9, 2, 103-10, 2006

[16] Nataro J.P., Kaper J.P., Diarrheagenic E. coli, CLin. Microbiol. Rev., 11, 142-201, 1998

[17] Scaletsky I. C. A., M. L. M. Silva, L. R. Trabulsi, Distinctive patterns of adherence of enteropathogenic Escherichia coli to HeLa cells, Infect. Immun. 45, 534-536, 1984

[18] Bieber D., Ramer S. W., Wu C. Y., Murray W. J., Tobe T., Fernandez R., Schoolnik G. K., Type IV pili, transient bacterial aggregates, and virulence of enteropathogenic Escherichia coli, Science 280, 2114-2118, 1998

[19] Hicks S., Frankel G., Kaper J. B., Dougan G., Phillips A. D., Role of intimin and bundle-forming pili in enteropathogenic Escherichia coli adhesion to pediatric intestinal tissue in vitro, Infect. Immun., 66, $1570-1578,1998$

[20] Hemmingsen S.M., Woolford C., Van der Vies S.M., Tilly K., Dennis D.T., Georgopoulos C.P., Hendrix R.W., Ellis R.J., Homologous and bacterial proteins chaperone oligomeric protein assembly, Nature, 333, 330-335, 1988

[21] Goloubinoff, P., Gatenby A.A., Lorimer G.H., GroEL heat-shock proteins promote assembly of foreign prokaryotic ribulose biphosphate carboxylase oligomers in Escherichia coli., Nature, 337, 4447, 1989

[22] Ewalt, K.L., Hendrick J.P., Houry W.A., Hartl F.U., In vivo observation of polypeptide flux through the bacterial chaperonin system, Cell, 90, 491-500, 1997

[23] Paradis S., Boissinot M., Paquette N., Bélanger S.D., Martel E.A., Boudreau D.K., Picard F.J.,Ouellette M., Roy P.H., Bergeron M.G., Phylogeny of the Enterobacteriaceae based on genes encoding elongation factor Tu and F-ATPase $\beta$-subunit, Int J Syst Evol Microbiol 55, 2013-2025, 2005 